\title{
Clinical efficacy and safety between high-intensity focused ultrasound and uterine artery embolization for cesarean scar pregnancy: a systematic review and a meta-analysis
}

\author{
Wei Mi" ${ }^{1 \#}$, Pei Pei ${ }^{2 \#}$, Yuan Zheng ${ }^{3}$ \\ ${ }^{1}$ Department of Ultrasound, Huangshi Maternity \& Children's Health Hospital, Edong Healthcare Group, Women's \& Children's Hospital Affiliated \\ to Hubei Polytechnic University, Huangshi, China; ${ }^{2}$ Department of Neurology, Huangshi Central Hospital, Affiliated Hospital of Hubei Polytechnic \\ University, Edong Healthcare Group, Huangshi, China; ${ }^{3}$ Department of Ultrasonic Imaging Division, Huangshi Central Hospital, Affiliated \\ Hospital of Hubei Polytechnic University, Edong Healthcare Group, Huangshi, China \\ Contributions: (I) Conception and design: W Mi; (II) Administrative support: W Mi; (III) Provision of study materials or patients: P Pei; (IV) \\ Collection and assembly of data: P Pei; (V) Data analysis and interpretation: Y Zheng; (VI) Manuscript writing: All authors; (VII) Final approval of \\ manuscript: All authors. \\ "These authors contributed equally to this work as co-first authors. \\ Correspondence to: Yuan Zheng. Department of Ultrasonic Imaging Division, Huangshi Central Hospital, Affiliated Hospital of Hubei Polytechnic \\ University, Edong Healthcare Group, 293 Hospital Street, Xisaishan District, Huangshi 435000, China. Email: yuanzheng98765@sina.com.
}

Background: It was reported that high-intensity focused ultrasound (HIFU) of cesarean scar pregnancy (CSP) can locally inactivate pregnancy tissue. Uterine artery embolization (UAE) can achieve good results for CSP too. To investigate the clinical efficacy and safety of HIFU and UAE in the treatment of cesarean scar pregnancy (CSP), we conducted this research.

Methods: Multiple databases were used to search for relevant studies and articles related to HIFU, UAE, and CSP. The selected literature were retrospectively evaluated using Review Manager 5.2. In addition, forest plots, sensitivity analysis, and bias analysis were conducted for the included literature.

Results: Finally, 8 related studies met the inclusion criteria. There were no significant differences in postoperative adverse reactions and hospitalization time between the HIFU group and the UAE group. However, the normalization time of serum beta human chorionic gonadotropin (B-HCG) in the HIFU group was higher than that in the UAE group $[\mathrm{MD}=1.16,95 \%$ confidence interval $(\mathrm{CI}), 0.09,2.22, \mathrm{P}=0.03$, $\left.\mathrm{I}^{2}=93 \%\right]$, and the hospitalization cost in the HIFU group was significantly lower than that in the UAE group $\left(\mathrm{MD}=-8.81,95 \% \mathrm{CI},-12.64,-4.97, \mathrm{P}<0.00001, \mathrm{I}^{2}=99 \%\right)$.

Discussion: Our results show that HIFU and UAE have the same curative effect in the treatment of CSP, but HIFU has lower cost and fewer complications. These results supported that compared with UAE, HIFU is a better choice for CSP patients with long gestational age, large gestational sac diameter and high HCG level.

Keywords: High-intensity focused ultrasound (HIFU); uterine artery embolization (UAE); cesarean scar pregnancy (CSP)

Submitted Feb 26, 2021. Accepted for publication Jun 04, 2021.

doi: 10.21037/apm-21-839

View this article at: https://dx.doi.org/10.21037/apm-21-839 


\section{Introduction}

Cesarean scar pregnancy (CSP) refers to an ectopic pregnancy in which the pregnancy sac or embryo sac is implanted on the scar site of a previous cesarean section. It results in a difficult, abnormal pregnancy. In recent years, the incidence of CSP in China has shown an increasing trend year by year. The exact etiology and pathogenesis of the disease are still unclear $(1,2)$. The clinical manifestations are mainly irregular vaginal bleeding, which may be accompanied by abdominal pain. However, $36.8 \%$ of patients are asymptomatic and can be diagnosed by auxiliary examinations such as ultrasound and endoscopy. The risk factors for infertility and recurrence of CSP after previous CSP include age, antenatal BMI of pregnant women, history of vaginal delivery, and baby weight.

High-intensity focused ultrasound (HIFU) uses the physical characteristics of ultrasound, such as tissue penetration and focusability, to focus low-energy ultrasound to target tissues in the body, and uses the high temperature generated by high-intensity ultrasound at the focal point. This results in coagulative necrosis of the diseased tissue, in order to achieve the purpose of non-invasive treatment (3-5). In clinical practice, HIFU technology is mainly used to treat solid tumors of the abdomen, soft tissue and bone tumors of the limbs, and soft tissue tumors on the body surface. Studies have shown that HIFU treatment of CSP can locally inactivate pregnancy tissue. It is a safe and effective noninvasive technique and its efficacy has been widely verified in the treatment of benign gynecological diseases such as adenomyosis and uterine fibroids. It is also used in the treatment of CSP assisted uterine evacuation $(6,7)$.

Uterine artery embolization (UAE) has been used in the treatment of obstetric and gynecological diseases such as uterine fibroids and postpartum hemorrhage since the 1990s (8-10). In recent years, with the development of interventional therapy technology, it has become minimally invasive, safe, and effective. UAE is widely used by domestic and foreign physicians to treat CSP, and can effectively control vaginal bleeding and reduce the risk of hysterectomy $(11,12)$. At the same time, infusion of methotrexate in the uterine artery can increase the local drug concentration, improve the germ-killing effect, and quickly and effectively stop bleeding, providing necessary conditions for future uterine treatment to preserve the patient's uterus and fertility (13-15). And uterine artery embolization treatment of cervical pregnancy can achieve good results, and less intraoperative blood loss, less complications, high safety.

In order to investigate the clinical efficacy and safety of HIFU and UAE in the treatment of CSP, this meta-analysis was conducted to better understand their overall diagnostic performance and help maximize the clinical utility of these 2 kinds of diagnostic approaches. In this research, we presented the following article in accordance with the PRISMA reporting checklist (available at https://dx.doi. org/10.21037/apm-21-839).

\section{Methods}

\section{Literature search strategy}

We searched for related articles published from January 2005 to March 2020, in order to provide a theoretical basis for choosing the better diagnostic method. The Cochrane Library, PubMed, EMBASE, MEDLINE, Central, and Web of Science were searched with the following keywords: (I) high intensity focused ultrasound; (II) uterine artery embolization; (III) cesarean scar pregnancy. Search terms were combined using the Boolean operator "AND" with the aim of obtaining different articles that included 2 or more of the terms used for the search. No restrictions regarding the publication language were used in the literature retrieval step. Reference lists of retrieved articles were screened manually to ensure sensitivity of the search strategy and to identify additional relevant studies.

\section{Study selection}

A full-text review of online publications determined after the preliminary selection of studies was conducted, and the included studies had to meet the following inclusion criteria:

(I) HIFU was used;

(II) UAE was used;

(III) CSP patients.

We systematically excluded the studies that did not meet the inclusion criteria according to the following exclusion criteria:

(I) Research involving other health problems;

(II) Patients received other diagnostic techniques;

(III) Lack of research on the existing data.

\section{Data extraction and quality assessment}

Two reviewers extracted data from full length articles 


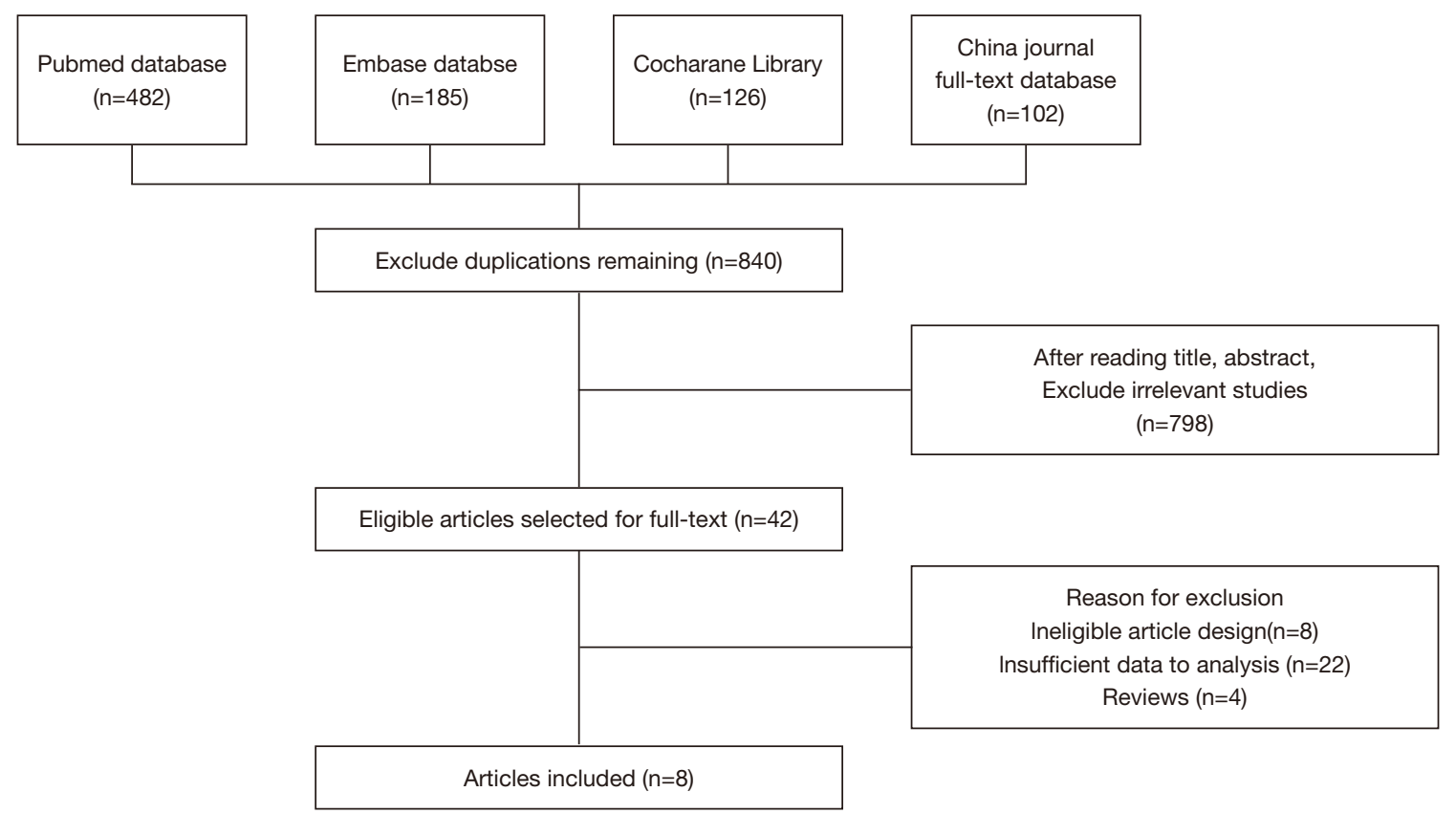

Figure 1 Flow diagram of the study selection.

independently. The collected data for each study included publication date, first author, country, number of patients recruited and randomized per study, age (years), and recruitment period. We also extracted the data of the following indicators: adverse reactions, serum beta human chorionic gonadotropin (B-HCG) normalization time, length of hospital stay, and treatment costs. We evaluated the quality of the involved trials using the Cochrane Collaboration's tool for assessing risk of bias. The risk of each domain was rated as high risk, unclear risk, or low risk according to the match level between the information extracted and the evaluation criteria.

It is worth noting that the authors tried to be fair in the quality assessment process, but the scores may have risen or fallen slightly. The manuscript met the applicable EQUATOR criteria.

\section{Statistical analysis}

For dichotomous variables, the odds ratio and $95 \%$ confidence interval (CI) were derived for each outcome. For continuous variables, we calculated the weighted mean difference and $95 \% \mathrm{CI}$.

The chi-squared test (Cochrane's Q test) and $\mathrm{I}^{2}$ statistical test were used to analyze the heterogeneity between studies. Statistical heterogeneity was measured using the chi- squared test on the Q statistic, which was quantified by $\mathrm{I}^{2}$ values, assuming that $\mathrm{I}^{2}$ values of $25 \%, 50 \%$, and $75 \%$ were nominally assigned as low, moderate, and high estimates, respectively. If the $\mathrm{I}^{2}$ value was greater than $50 \%$, there was moderate heterogeneity between studies. The effect size of each study was calculated using the DerSimonian and Laird random-effect model.

Publication bias was analyzed using a funnel plot and quantified with rank correlation. To assess the effect of an individual study on the pooled estimate, we performed a sensitivity analysis by omitting each study in turn. Data synthesis and statistical analysis were carried out using Review Manager Version 5.2 software.

\section{Results}

\section{Search process}

A total of 840 articles were identified by searching the electronic databases. After careful reading, 42 papers met the preliminary standard. After further screening, 34 articles were excluded due to ineligible research design and insufficient data and article types. Finally, 8 articles were selected and these papers were included in this meta-analysis. Figure 1 (flow chart) describes the process of study identification and inclusion, and the reasons for exclusion. 
Table 1 Characteristics of studies included in the meta-analysis

\begin{tabular}{lccccccc}
\hline Study & Year & Language & Country & Age (mean) & No. in HIFU group & No. in UAE group Years of onset \\
\hline Chen et al. & 2018 & English & China & $35 \pm 6.5$ & 68 & 67 & January 2007 to April 2016 \\
Chu et al. & 2018 & Chinese & China & $30.7 \pm 4.2$ & 102 & 90 & January 2014 to June 2016 \\
Dai et al. & 2017 & Chinese & China & $29.76 \pm 3.6$ & 90 & 62 & January 2014 to May 2016 \\
Hong et al. & 2017 & English & China & $32.37 \pm 4.3$ & 85 & 67 & September 2014 to January 2016 \\
Lin et al. & 2020 & Chinese & China & $30.85 \pm 6.95$ & 55 & 61 & October 2015 to October 2017 \\
Wang et al. & 2020 & Chinese & China & $30.85 \pm 6.95$ & 96 & 46 & January 2013 to June 2018 \\
Xiao et al. & 2016 & English & China & $31.36 \pm 4.28$ & 31 & 45 & October 2012 to September 2014 \\
Zhu et al. & 2016 & English & China & $31.95 \pm 5.05$ & 76 & 46 & January 2014 to December 2014 \\
\hline
\end{tabular}

HIFU, high-intensity focused ultrasound; UAE, uterine artery embolization.

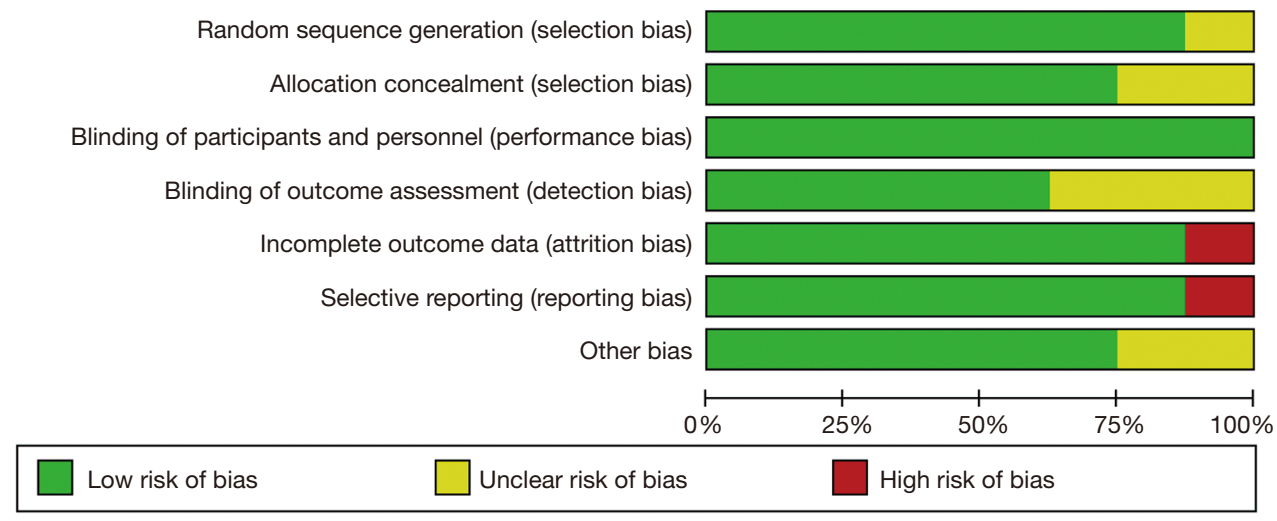

Figure 2 Risk of bias summary, with high risk of bias (red), low risk of bias (green), and unclear risk of bias (yellow).

\section{Characteristics of included studies}

Table 1 summarizes the types of studies reported and the total number of patients associated with each group (16-25). The content included author, year of publication, country, language, age, group, sample size, and recruitment time. The analysis included 4,665 patients. From 2007 to 2018, all the 8 articles were published. The sample size ranged from 76 to 192. There were 603 cases in the HIFU group and 484 cases in the UAE group.

\section{Results of the quality assessment}

We used the Cochrane risk bias assessment tool to evaluate the quality of the included trials and the Review Manager 5.2 software to analyze the data. The risk of bias in this study is shown in Figure 2, with little bias between the HIFU and UAE groups. Figure 3 shows the details of the quality assessment in this study. As shown in Figure 3, the overall risk of all 8 papers was low.

\section{Results of the beterogeneity test}

Figure 4 shows the forest plot of the number of adverse reactions after treatment in the HIFU and UAE groups. Seven studies were included in the comparison, and the analysis showed no difference between the two groups $\left(\mathrm{OR}=0.72,95 \% \mathrm{CI}, 0.22,2.29, \mathrm{P}=0.57, \mathrm{I}^{2}=86 \%\right)$.

Figure 5 shows the forest plot of the normalization time of serum B-HCG after treatment of CSP in the HIFU and UAE groups. Four studies were included in this comparison. The data obtained showed differences between the two groups. The normalization time of serum B-HCG in the HIFU group was higher than that in the UAE group ( $\left.\mathrm{MD}=1.16,95 \% \mathrm{CI}, 0.09,2.22, \mathrm{P}=0.03, \mathrm{I}^{2}=93 \%\right)$.

Figure 6 shows a forest plot of the length of hospital stay 


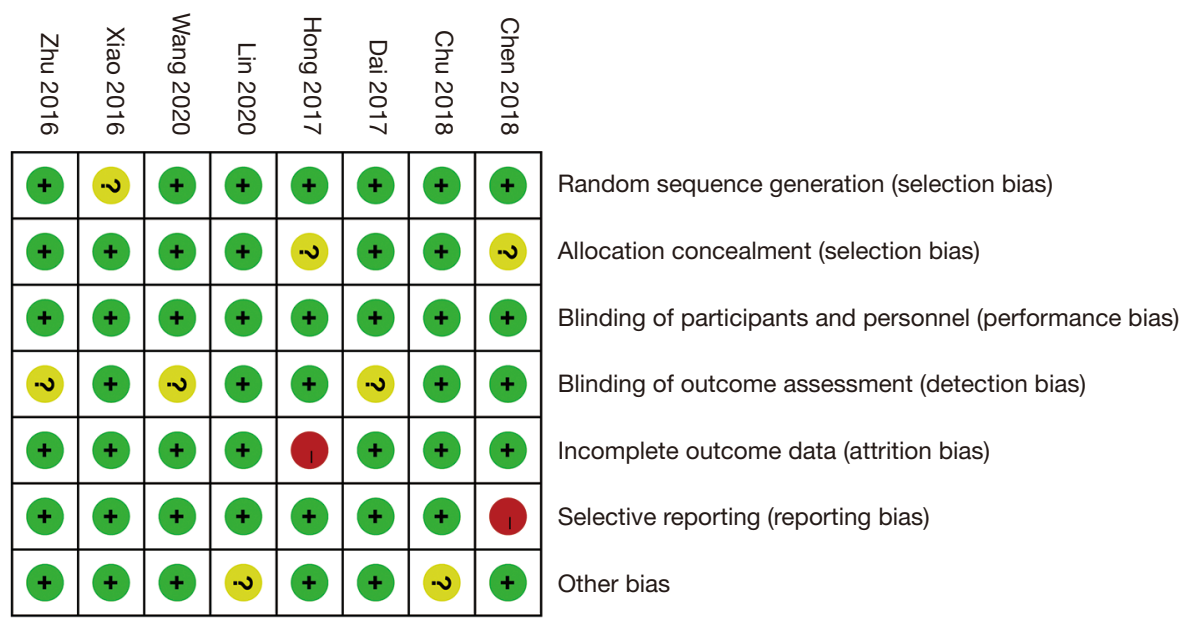

Figure 3 Quality assessment of the included studies. Green represented low risk, red represented high risk and yellow represented unclear risk.

\begin{tabular}{|c|c|c|c|c|c|c|c|c|c|c|}
\hline Study or Subgroup & $\begin{array}{c}\text { HIFU } \\
\text { Events }\end{array}$ & Total & $\begin{array}{l}\text { UAE } \\
\text { Events }\end{array}$ & Total & Weight & $\begin{array}{c}\text { Odds Ratio } \\
\text { M-H, Random. } 95 \% \mathrm{Cl}\end{array}$ & & $\begin{array}{r}\text { Odds } \\
\text { M-H, Rando }\end{array}$ & $\begin{array}{l}\text { Ratio } \\
\text { lom. } 95 \% \mathrm{Cl}\end{array}$ & \\
\hline Chu 2018 & 8 & 102 & 20 & 90 & $15.7 \%$ & $0.30[0.12,0.72]$ & & -1 & & \\
\hline Dai 2017 & 1 & 90 & 4 & 62 & $10.6 \%$ & $0.16[0.02,1.49]$ & & & & \\
\hline Hong 2017 & 6 & 85 & 13 & 67 & $15.2 \%$ & $0.32[0.11,0.88]$ & & & & \\
\hline Lin 2020 & 41 & 55 & 14 & 61 & $15.8 \%$ & $9.83[4.20,23.03]$ & & & & \\
\hline Wang 2020 & 4 & 96 & 3 & 46 & $13.3 \%$ & $0.62[0.13,2.91]$ & & & & \\
\hline Xiao 2016 & 5 & 31 & 9 & 45 & $14.6 \%$ & $0.77[0.23,2.56]$ & & & & \\
\hline Zhu 2016 & 8 & 76 & 6 & 46 & $14.8 \%$ & $0.78[0.25,2.42]$ & & & & \\
\hline Total $(95 \% \mathrm{Cl})$ & & 535 & & 417 & $100.0 \%$ & $0.72[0.22,2.29]$ & & & & \\
\hline Total events & 73 & & 69 & & & & & & & \\
\hline \multicolumn{7}{|c|}{$\begin{array}{l}\text { Heterogeneity: } \mathrm{Tau}^{2}=2.05 ; \mathrm{Chi}^{2}=43.12, \mathrm{df}=6(P<0.00001) ;\left.\right|^{2}=86 \% \\
\text { Test for overall effect: } Z=0.56(P=0.57)\end{array}$} & $\frac{1}{0.002}$ & $\underset{\text { HIFU }}{0.1} 1$ & $\begin{array}{l}10 \\
\text { UAE }\end{array}$ & 500 \\
\hline
\end{tabular}

Figure 4 Forest plot of the incidence of adverse reactions after treatment of CSP in the two groups. CSP, cesarean scar pregnancy.

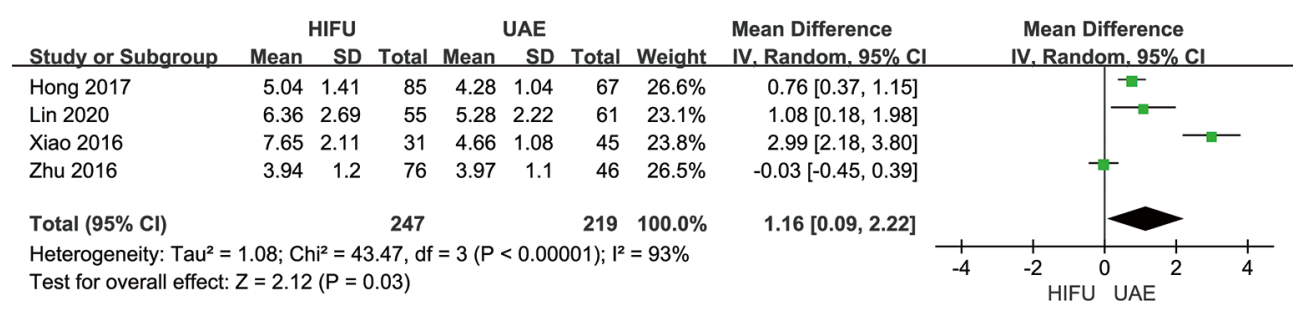

Figure 5 Forest plot of the normalization time of serum B-HCG after CSP treatment in the two groups. B-HCG, beta human chorionic gonadotropin; CSP, cesarean scar pregnancy.

in the HIFU and UAE groups. Six studies were included in the comparison, and the analysis showed no difference between the two groups ( $\mathrm{MD}=-0.21,95 \% \mathrm{CI},-0.64,0.22$, $\left.\mathrm{P}=0.34, \mathrm{I}^{2}=67 \%\right)$.

Figure 7 shows a forest plot of hospitalization expenses in the HIFU and UAE groups. Four studies were included in the comparison. The results showed that there was a difference between the two groups. The hospitalization cost in the HIFU group was significantly lower than that in the UAE group $\left(\mathrm{MD}=-8.81,95 \% \mathrm{CI},-12.64,-4.97, \mathrm{P}<0.00001, \mathrm{I}^{2}=99 \%\right)$.

\section{Results of the sensitivity analysis and publication bias}

Sensitivity analysis was conducted in order to evaluate the 


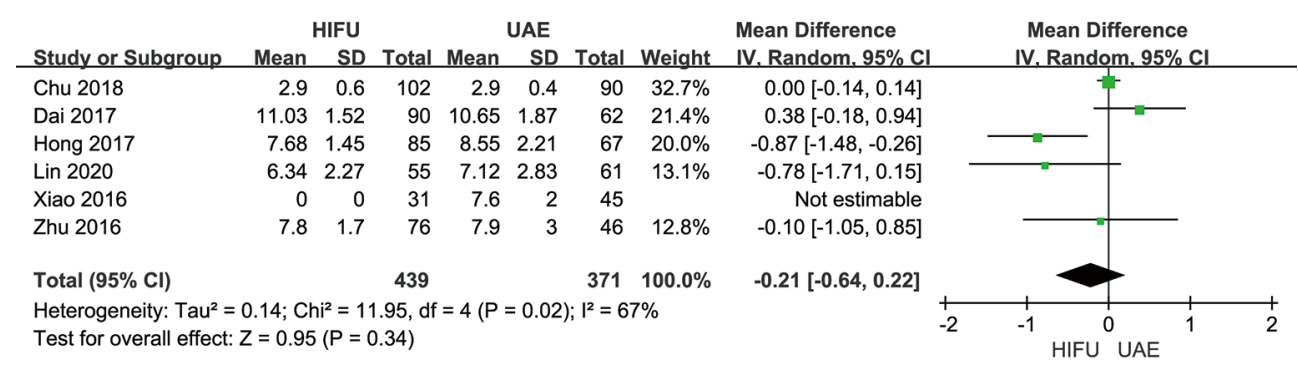

Figure 6 Forest plot of the length of hospital stay after treatment of CSP in the two groups. CSP.

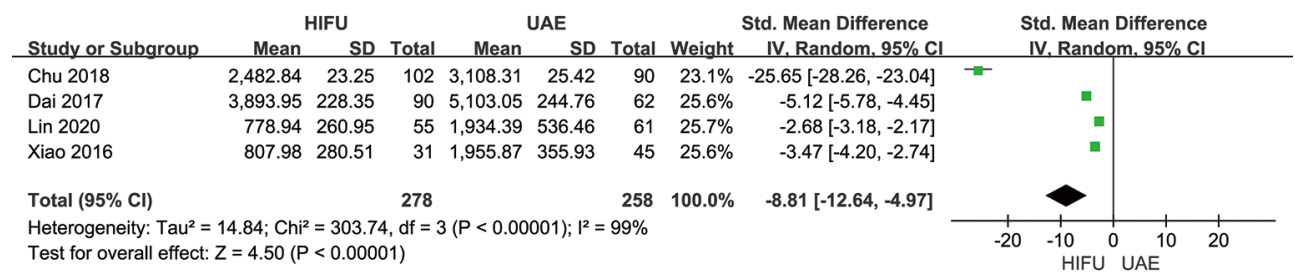

Figure 7 Forest plot of the hospitalization expenses of the two groups for treatment of CSP. CSP, cesarean scar pregnancy.

\begin{tabular}{|c|c|c|c|c|c|c|c|c|c|c|}
\hline Study or Subgroup & $\begin{array}{l}\text { HIFU } \\
\text { Events }\end{array}$ & Total & $\begin{array}{l}\text { UAE } \\
\text { Events }\end{array}$ & Total & Weight & $\begin{array}{c}\text { Odds Ratio } \\
\text { M-H, Random, } 95 \% \mathrm{Cl}\end{array}$ & & $\begin{array}{r}\text { Odds } \\
\text { M-H, Rand } \\
\end{array}$ & $\begin{array}{l}\text { Ratio } \\
\text { dom. } 95 \% \mathrm{Cl}\end{array}$ & \\
\hline Chu 2018 & 8 & 102 & 20 & 90 & $17.6 \%$ & $0.30[0.12,0.72]$ & & -- & & \\
\hline Hong 2017 & 6 & 85 & 13 & 67 & $17.0 \%$ & $0.32[0.11,0.88]$ & & & & \\
\hline Lin 2020 & 41 & 55 & 14 & 61 & $17.7 \%$ & $9.83[4.20,23.03]$ & & & $\rightarrow$ & \\
\hline Wang 2020 & 4 & 96 & 3 & 46 & $14.8 \%$ & $0.62[0.13,2.91]$ & & & & \\
\hline Xiao 2016 & 5 & 31 & 9 & 45 & $16.3 \%$ & $0.77[0.23,2.56]$ & & & & \\
\hline Zhu 2016 & 8 & 76 & 6 & 46 & $16.6 \%$ & $0.78[0.25,2.42]$ & & & & \\
\hline Total $(95 \% \mathrm{Cl})$ & & 445 & & 355 & $100.0 \%$ & $0.85[0.25,2.94]$ & & & & \\
\hline Total events & 72 & & 65 & & & & & & & \\
\hline \multicolumn{7}{|c|}{$\begin{array}{l}\text { Heterogeneity: } \mathrm{Tau}^{2}=2.07 ; \mathrm{Chi}^{2}=40.69, \mathrm{c} \\
\text { Test for overall effect: } Z=0.25(P=0.80)\end{array}$} & $\frac{1}{0.002}$ & $\begin{array}{l}0.1 \\
\text { HIFU }\end{array}$ & $1{ }^{10}$ & 500 \\
\hline
\end{tabular}

Figure 8 Sensitivity analysis of the incidence of adverse reactions after treatment of CSP in the two groups. CSP, cesarean scar pregnancy.

stability of the analysis results. Excluding a relative outlier, the sensitivity of the value changed from $86 \%$ to $88 \%$ in the heterogeneity part. The results showed that this heterogeneity was mainly due to Dai et al.'s research in 2017 (22). The forest plot without Dai et al.'s article is shown in Figure 8.

A funnel plot for publication bias was generated. Seven studies were included in the plot. The publication bias was estimated by the visual symmetry of the funnel plot. The symmetrical funnel plot indicated that there was no significant publication bias in this study (Figure 9).

\section{Discussion}

We identified 8 studies that met the inclusion criteria to evaluate the efficacy and safety of HIFU and UAE in the treatment of CSP (24,25). Meta-analysis of these studies showed that both HIFU and UAE were effective in the treatment of CSP, but HIFU cost less, was safer, was more effective, and was more suitable as an adjuvant therapy for CSP.

CSP refers to ectopic pregnancy in which the fertilized egg is implanted in the previous cesarean scar. It is rare and can lead to placenta accreta, uterine rupture, and even maternal death. It is a potential long-term serious complication after cesarean section (26-28). In the recent 10 years, with the deepening understanding of the disease, the experience and efficacy of clinical diagnosis and treatment have constantly accumulated and improved. 


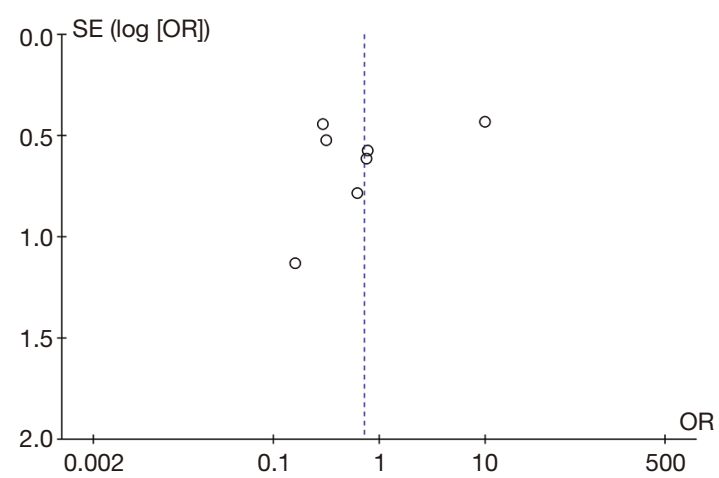

Figure 9 Funnel plot of publication bias.

Due to the variety of clinical features and manifestations of CSP, there is currently no unified treatment standard. The main treatment methods include HIFU, UAE, and local puncture, amongst others $(29,30)$.

HIFU is a new clinical treatment technology which has developed in recent years. It is a non-invasive ablation therapy. It focuses the ultrasound on the target area in the organism to form a high-intensity ultrasound convergence area. The biological thermal effect produced by ultrasound results in coagulative necrosis of the tissue in this area under the effect of high temperature, so as to achieve the purpose of treatment (31-33). The advantages are that it is non-invasive, accurate, repeatable. The effect of highintensity focused ultrasound combined with hysteroscopy in the treatment of re-pregnancy at the scar site after cesarean section is quite significant, which can shorten the operation time and increase the patient's uterine retention rate. UAE is a modern medical image-guided technology for the treatment of uterine fibroids, and is a type of vascular invasive surgery $(34,35)$. The operation mainly uses modern medical equipment such as computed tomography, ultrasound, nuclear magnetic resonance, laparoscopy, and $\mathrm{X}$-ray to make the diagnosis, and then carries out directional surgery on the lesion tissue to achieve the purpose of treatment. UAE has many advantages, and it is one of the main methods used to treat CSP because of the characteristics of rapid blood transfusion, less trauma, more selective retreatment, and fertility preservation.

HIFU and UAE have the same curative effect in the treatment of CSP, however, HIFU causes fewer adverse reactions and postoperative complications, so it is more suitable as an adjuvant treatment for CSP (36-38). In addition, there are some limitations in this article. Firstly, the probability of re-pregnancy after surgery was not compared and should be evaluated in further studies. Secondly, the sample countries could have included more areas, which should be included in future work.

\section{Acknowledgments}

Funding: None.

\section{Footnote}

Reporting Checklist: The authors have completed the PRISMA reporting checklist. Available at https://dx.doi. org/10.21037/apm-21-839

Conflicts of Interest: All authors have completed the ICMJE uniform disclosure form (available at https://dx.doi. org/10.21037/apm-21-839). The authors have no conflicts of interest to declare.

Etbical Statement: The authors are accountable for all aspects of the work in ensuring that questions related to the accuracy or integrity of any part of the work are appropriately investigated and resolved.

Open Access Statement: This is an Open Access article distributed in accordance with the Creative Commons Attribution-NonCommercial-NoDerivs 4.0 International License (CC BY-NC-ND 4.0), which permits the noncommercial replication and distribution of the article with the strict proviso that no changes or edits are made and the original work is properly cited (including links to both the formal publication through the relevant DOI and the license). See: https://creativecommons.org/licenses/by-nc-nd/4.0/.

\section{References}

1. Zheng J, He Y, Liu S, et al. Analysis of 43 cases of cesarean scar pregnancy treated with suction curettage under ultrasound guidance. Zhonghua Fu Chan Ke Za Zhi 2015;50:582-5.

2. Yu H, Luo H, Zhao F, et al. Successful selective reduction of a heterotopic cesarean scar pregnancy in the second trimester: a case report and review of the literature. BMC Pregnancy Childbirth 2016;16:380.

3. Yang H, Li S, Ma Z, et al. Therapeutic effects of uterine artery embolisation (UAE) and methotrexate (MTX) conservative therapy used in treatment of cesarean scar pregnancy. Arch Gynecol Obstet 2016;293:819-23. 
4. Wang Q, Peng HL, He L, et al. Reproductive outcomes after previous cesarean scar pregnancy: Follow up of 189 women. Taiwan J Obstet Gynecol 2015;54:551-3.

5. Vimercati A, de Gennaro AC, Resta L, et al. Sonographic and Power Doppler Evaluation of an Invasive Mole Located in a Cesarean Scar Pregnancy. J Ultrasound Med 2016;35:1608-12.

6. Vidal-Jove J, Perich E, Del Castillo MA. Ultrasound Guided High Intensity Focused Ultrasound for malignant tumors: The Spanish experience of survival advantage in stage III and IV pancreatic cancer. Ultrason Sonochem 2015;27:703-6.

7. Vetter MH, Andrzejewski J, Murnane A, et al. Surgical Management of a Heterotopic Cesarean Scar Pregnancy With Preservation of an Intrauterine Pregnancy. Obstet Gynecol 2016;128:613-6.

8. Timor-Tritsch IE, Monteagudo A, Bennett TA, et al. A new minimally invasive treatment for cesarean scar pregnancy and cervical pregnancy. Am J Obstet Gynecol 2016;215:351.e1-8.

9. Almekkaway MK, Shehata IA, Ebbini ES. Anatomicalbased model for simulation of HIFU-induced lesions in atherosclerotic plaques. Int J Hyperthermia 2015;31:433-42.

10. Qiu J, Fu Y, Huang X, et al. Acute pulmonary embolism in a patient with cesarean scar pregnancy after receiving uterine artery embolization: a case report. Ther Clin Risk Manag 2018;14:117-20.

11. Polat I, Ekiz A, Acar DK, et al. Suction curettage as first line treatment in cases with cesarean scar pregnancy: feasibility and effectiveness in early pregnancy. J Matern Fetal Neonatal Med 2016;29:1066-71.

12. Pirjani R, Bayani L, Shirazi M. Successful local and systemic medical treatment of cesarean scar pregnancy and a subsequent term pregnancy after treatment: a case series. Iran J Reprod Med 2015;13:445-50.

13. Peng P, Gui T, Liu X, et al. Comparative efficacy and safety of local and systemic methotrexate injection in cesarean scar pregnancy. Ther Clin Risk Manag 2015;11:137-42.

14. Peng M, Li L, Ding Y, et al. Exploration of the Successful Treatment Algorithms Used in 23 Cases of Early Live Cesarean Scar Pregnancy. Gynecol Obstet Invest 2015;79:139-44.

15. Birge Ö, Karaca C, Arslan D, Kinali E. Medical management of cesarean scar pregnancy at advanced age: case report and literature review. Clin Exp Obstet Gynecol 2016;43:140-2.
16. Zhu X, Deng X, Xiao S, et al. A comparison of highintensity focused ultrasound and uterine artery embolisation for the management of caesarean scar pregnancy. Int J Hyperthermia 2016;32:144-50.

17. Zhen-jiang L, Li Y, Song L, et al. Comparison of the effectiveness and safety of high-intensity focused ultrasound and uterine artery embolization-assisted vacuum aspiration in the treatment of pregnancy at the scar site of cesarean section. Chinese Journal of Practical Gynecology and Obstetrics 2020;36:365-9.

18. Xiao J, Shi Z, Zhou J, et al. Cesarean Scar Pregnancy: Comparing the Efficacy and Tolerability of Treatment with High-Intensity Focused Ultrasound and Uterine Artery Embolization. Ultrasound Med Biol 2017;43:640-7.

19. Wang Y, Li Q, Yang N, et al. The effect of high-intensity focused ultrasound treatment of scar pregnancy on ovarian reserve. Armed Police Medicine 2020;31:378-81.

20. Chen L, Xiao S, Zhu X, et al. Analysis of the Reproductive Outcome of Patients with Cesarean Scar Pregnancy Treated by High-Intensity Focused Ultrasound and Uterine Artery Embolization: A Retrospective Cohort Study. J Minim Invasive Gynecol 2019;26:883-90.

21. Hong Y, Guo Q, Pu Y, et al. Outcome of high-intensity focused ultrasound and uterine artery embolization in the treatment and management of cesarean scar pregnancy: A retrospective study. Medicine (Baltimore) 2017;96:e7687.

22. Dai Q, Zheng A, Wang W, et al. A prospective comparative study of high-intensity focused ultrasound and uterine artery embolization in the treatment of cesarean scar pregnancy. West China Medicine 2017;32:723-26.

23. Chu G, Liu C, Hu C, et al. Comparison of the clinical effects of high-intensity focused ultrasound and uterine artery embolization in the auxiliary treatment of cesarean section scar pregnancy. Chinese Journal of Maternal and Child Clinical Medicine 2018;14:547-52.

24. Murugappan SK, Zhou Y. Transsclera Drug Delivery by Pulsed High-Intensity Focused Ultrasound (HIFU): An Ex Vivo Study. Curr Eye Res 2015;40:1172-80.

25. Guo MH, Wang MF, Liu MM, et al. Management of Cesarean Scar Pregnancy: A Case Series. Chin Med Sci J 2015;30:226-30.

26. Liu G, Wu J, Cao J, et al. Comparison of three treatment strategies for cesarean scar pregnancy. Arch Gynecol Obstet 2017;296:383-9.

27. Li YR, Xiao SS, Wan YJ, et al. Analysis of the efficacy of three treatment options for cesarean scar pregnancy management. J Obstet Gynaecol Res 2014;40:2146-51.

28. Li $Y$, Wang W, Yang T, et al. Incorporating uterine artery 
embolization in the treatment of cesarean scar pregnancy following diagnostic ultrasonography. Int J Gynaecol Obstet 2016;134:202-7.

29. Kröncke T, David M. Uterine Artery Embolization (UAE) for Fibroid Treatment--Results of the 5th Radiological Gynecological Expert Meeting. Rofo 2015;187:483-5.

30. Kauffman RP. Treatment of cesarean scar pregnancy: another chapter in the fertility preservation saga. Fertil Steril 2016;105:895-6.

31. Shui L, Mao S, Wu Q, et al. High-intensity focused ultrasound (HIFU) for adenomyosis: Two-year follow-up results. Ultrason Sonochem 2015;27:677-81.

32. Zhang $\mathrm{H}$, Huang J, Wu X, et al. Clinical classification and treatment of cesarean scar pregnancy. J Obstet Gynaecol Res 2017;43:653-61.

33. Han H, Lee H, Kim K, et al. Effect of high intensity focused ultrasound (HIFU) in conjunction with a nanomedicines-microbubble complex for enhanced drug delivery. J Control Release 2017;266:75-86.

34. Gao L, Huang Z, Zhang X, et al. Reproductive outcomes

Cite this article as: Mi W, Pei P, Zheng Y. Clinical efficacy and safety between high-intensity focused ultrasound and uterine artery embolization for cesarean scar pregnancy: a systematic review and a meta-analysis. Ann Palliat Med 2021;10(6):63796387. doi: 10.21037/apm-21-839 following cesarean scar pregnancy - a case series and review of the literature. Eur J Obstet Gynecol Reprod Biol 2016;200:102-7.

35. Czuczwar P, Wozniak S, Szkodziak P, et al. Influence of ulipristal acetate therapy compared with uterine artery embolization on fibroid volume and vascularity indices assessed by three-dimensional ultrasound: prospective observational study. Ultrasound Obstet Gynecol 2015;45:744-50.

36. Cok T, Kalayci H, Ozdemir H, et al. Transvaginal ultrasound-guided local methotrexate administration as the first-line treatment for cesarean scar pregnancy: Follow-up of 18 cases. J Obstet Gynaecol Res 2015;41:803-8.

37. Chatillon S, Loyet R, Brunel L, et al. Applications of intensive HIFU simulation based on surrogate models using the CIVA HealthCare platform. Journal of Physics Conference 2021;1761:12007.

38. Cali G, Forlani F, Timor-Tritsch IE, et al. Natural history of Cesarean scar pregnancy on prenatal ultrasound: the crossover sign. Ultrasound Obstet Gynecol 2017;50:100-4. 